\title{
Depth and Breadth of Vocabulary Knowledge: Which Really Matters in Reading Comprehension of Iranian EFL Learners?
}

\author{
Ahmad Moinzadeh \\ Department of English, University of Isfahan, Isfahan, Iran \\ Email: moin@fgn.ui.ac.ir \\ Roghaieh Moslehpour \\ Department of English, University of Isfahan, Isfahan, Iran \\ Email: moslehpoorr19846@yahoo.com
}

\begin{abstract}
The present study tried to assess the roles of vocabulary knowledge in reading comprehension of Iranian EFL learners. Using the multivariate analysis, this study examined the roles of depth and breadth of vocabulary knowledge in reading comprehension of a group of Iranian EFL University students with a minimum vocabulary size of 3,000 word families as was measured by Schmitt's (2001) Vocabulary Levels Test. The study found that 1 ) the test scores on vocabulary breadth, vocabulary depth and reading comprehension are positively correlated and 2) vocabulary breadth was a stronger predictor of reading comprehension than depth of vocabulary knowledge for the participants of the present study.
\end{abstract}

Index Terms - breadth of vocabulary knowledge, depth of vocabulary knowledge, lexical threshold for reading comprehension

\section{INTRODUCTION}

Of the four language modes (listening, speaking, reading, and writing) in studying English as a foreign language, reading comprehension is considered one of the most important sources for language learning in an EFL setting. Reading is a complex process; reading in a foreign language is even more complex. Reading comprehension, in both first (L1) and second (L2) language, is affected by many variables, the most researched being background knowledge, and reading comprehension strategies (Grabe, 1991). Research on the relationship between L2 vocabulary knowledge and reading comprehension is just beginning to gain attention and very limited number of studies (e.g., Beglar and Hunt, 1999; de Bot, Paribakht,and Wesche, 1997; Laufer, 1992b) were conducted to determine what role vocabulary knowledge plays in reading comprehension.

In their attempts to define aspects and components of lexical knowledge, a number of second language (L2) lexical researchers (e.g., Read, 2004, 1989, 1988; Qian, 2002, 1999, 1998; Haastrup and Henriksen, 2000; Wesche and Paribakht, 1996; Meara, 1996) proposed that lexical knowledge could be regarded as having two primary dimensions: breadth and depth. Therefore, recognition of depth and breadth as two primary dimensions of vocabulary knowledge is essential to understanding the relationship between vocabulary knowledge and reading comprehension. In the present study, breadth of vocabulary is defined as the number of words for which a learner has at least some minimum knowledge of meaning and depth of vocabulary knowledge is defined as a learner's level of knowledge of various aspects of a given word.

The present study aimed to determine the contribution of vocabulary size and vocabulary depth to reading comprehension. It is worth mentioning that although all vocabulary dimensions are conceptually relevant in assessing the role of vocabulary knowledge in reading comprehension, only vocabulary size and a partial dimension of vocabulary depth (synonymy, polysemy, and collocation) was evaluated in this study because the measures of vocabulary size and vocabulary depth were incapable of assessing the other dimensions of vocabulary knowledge in a large-scale testing. Besides, three aspects of depth of vocabulary knowledge were measured since these aspects have been identified as the most fundamental among the depth of vocabulary knowledge aspects in almost all frameworks of vocabulary knowledge (e.g., Qian, 2002, 1999; Nation, 2001, 1990; Chapelle, 1998).

This research study tried to provide plausible answers to the following research questions:

1. Is there any relationship between Iranian EFL learners' depth of vocabulary knowledge and their performance in reading comprehension?

2. Is there any relationship between Iranian EFL learners' breadth of vocabulary knowledge and their performance in reading comprehension? 
3. For Iranian EFL learners at lexical threshold level for reading comprehension, does depth of vocabulary knowledge contribute more to their reading comprehension performance than vocabulary breadth?

\section{REVIEW OF RELATED LITERATURE}

\section{A. What is Involved in Knowing a Word?}

Over the years, lexical researchers have built up various criteria for understanding what is involved in knowing a word in second language (L2) research. In an earlier era, Cronbach (1942) classified vocabulary knowledge into five categories by focusing on word meaning (generalization, breadth of meaning, and precision of meaning) and use (application and availability). Realizing the restriction in Cronbach's (1942) framework, Richards (1976) integrated more aspects of lexical knowledge, such as morpho-syntactic properties, association, frequency level, and register into Cronbach's framework. Richards (1976) offered the following assumptions concerning what is involved in knowing a word: frequency, register, syntax, derivation, association, semantic features and polysemy.

Largely retaining Richard's (1976) definition of knowing a word, Nation (1990) added such important components as pronunciation and collocations to make the framework more comprehensive. He proposed 16 questions on what are necessary to fully know a word with the incorporation of the receptive-productive distinction. Later, Nation (2001) revised his earlier framework in order to improve the relatedness between various aspects of word knowledge and its practicability. Within his revised classification scheme, the refined 18 questions on knowing a word arose to reflect three different types of lexical knowledge- form (spoken form, written from, and word parts), meaning (form and meaning, concept, referents and associations), and use (grammatical functions, collocations, and constraints on use).

Taking into account the merits of the previous frameworks of lexical knowledge especially those of Nation (1990) and Richards (1976), Qian (1998) proposed a framework of lexical knowledge. This framework identifies very important aspects composing depth of vocabulary knowledge, i.e., pronunciation, morphological knowledge, syntactic properties, meaning, register or discourse features and frequency especially from the perspective of their possible contribution to reading comprehension process. Qian (2002) developed another framework on the collective strength of earlier models of vocabulary knowledge (e.g., Nation, 2001 Henriksen, 1999; Chapelle, 1998; Qian, 1998) for lexical knowledge which proposes that vocabulary knowledge comprises four intrinsically connected dimensions including vocabulary size and depth. Depth of vocabulary knowledge in this framework includes phoneme, grapheme, morpheme, syntax and semantic features. In Qian's (2002) model, as well as in all other frameworks (e.g., Nation, 2001, 1990; Henriksen, 1999; Qian, 1998; Chapelle, 1998) reviewed so far, there is a clear consensus that depth and size of vocabulary knowledge occupies a primary and central place in the multidimensional domain of vocabulary knowledge.

\section{B. Depth and Breadth of Vocabulary Knowledge}

In research on vocabulary knowledge, a distinction has been made between depth and breadth as the two primary dimensions of vocabulary knowledge by a number of lexical researchers (e.g. Read, 2004; Qian, 2002, 1999, 1998; Haastrup and Henriksen, 2000; Meara, 1996; Wesche and Paribakht, 1996). Nagy and Scott (2000) examined the breadth and depth of vocabulary and believed that a person who knows a word can recognize it, and use it, in novel contexts, and uses knowledge of the word in combination with other types of knowledge to construct meaning for a text. Furthermore, Schawanemflugel et al (1997) used the terms minimal, partial and full concept to describe breadth and depth of vocabulary. Language learners with minimal concept knowledge link new word with single context while language learners with full concept understand and use words in different contexts, know the varied meanings of multiple-meaning words and can ascertain a word's meaning from the meanings of similar words. Ordonez et.al. (2002), who examined the relationship between paradigmatic and syntagmatic word knowledge, also asserted that although lexical knowledge is most commonly thought of as a number of words known, it is now increasingly clear that richness of the representation of the words known, depth of vocabulary, is also a key dimension of variability.

Breadth of vocabulary knowledge has been taken to refer to the number of the words learners know at a particular level of proficiency (Nation, 2001; Qian, 2002 1999, 1998). According to Nation and Waring, (1997), there are around 54,000 word families in English. Nation and Waring (1997); however, reported the vocabulary size of an educated adult native speaker of English to be only around 20,000 word families. Although there are clearly differences across individuals, this estimate is generally accepted. In one research study, Nation (1993) found that adult learners of English as a foreign language (EFL) have vocabulary size of fewer than 5,000 word families, even after they have studied English for several years. Depth of lexical knowledge, on the other hand, has been used to refer to the quality of lexical knowledge or how well a learner knows a word (Read, 2004; Meara, 1996). Researchers have noted the complexity and multidimensionality of word knowledge and have suggested that knowing a word well should mean more than knowing its individual meaning in particular contexts (Qian, 1999). Various kinds of knowledge are associated with a word that a learner knows, ranging from knowledge related to its pronunciation, spelling, register, stylistic, and morphological features (Haastrup and Henriksen, 2000; Meara 1996; Nation, 1990; Richards, 1976) to knowledge of the word's syntactic and semantic relationships with other words in a language including collocational meaning and knowledge of antonymy, synonymy and hyponymy (Read, 2004; Henriksen, 1999; Chappelle, 1994).

C. Lexical Threshold for L2 Reading Comprehension 
The threshold hypothesis in reading postulates that in terms of vocabulary size there is a threshold level below which the reader will be handicapped by lack of comprehension and above which the reader will be able to apply his/her reading comprehension strategies to help comprehension and achieve better results (Laufer and Hulstijn, 2001; Laufer, 1997, 1996, 1992b, 1989; Clark, 1980, 1979; Nation, 1990; Cummins, 1979).

There exist various view points with regard to lexical threshold level which is necessary for successful reading comprehension. Sutarsyah, Nation and Kennedy (1994), for instance, suggested a minimum of 4,000-5,000 word families for comprehending a single university textbook in English which contains 5,438 word families. Furthermore, Hirsh and Nation (1992) suggested that for ease of reading, where reading could be a pleasurable activity, 98-99\% coverage is desirable (about one unknown word in every 50-100 running words). To reach 95\% coverage of academic text, a vocabulary size of around 4,000 word families would be needed, consisting of 2,000 high frequency general service words, about 570 general academic words (the Academic Word List) and 1,000 or more technical words, proper nouns and low frequency words. In her attempts to determine a lexical threshold level for reading comprehension of English language learners, Laufer (1996, 1992b, 1989) conducted a series of studies. In one earlier study, Laufer and Sim (1985a) used comprehension questions and interviews with learners to determine a threshold score where learners could be said to be able to comprehend an English for Academic Purposes text in the First Certificate in English (FCE) exam. They concluded that a score of $65-70 \%$ was the minimum vocabulary necessary. Laufer (1989) then went a step further to see what percentage of word tokens (running words) needed to be understood in order to ensure reasonable reading comprehension of the text. Laufer (1989) found that the group that scored $95 \%$ and above on the vocabulary measure had a significantly higher number of successful readers than those scoring below 95\%.The $90 \%$ level did not result in significant differences between those above and below. A comparison of the $95 \%$ and above group with the 90 $94 \%$ group revealed a significant difference in comprehension scores. Laufer (1992b) in a further study looked at the relationship between reading comprehension score and vocabulary size, as measured by the Vocabulary Levels Test (Nation, 1983) or the Eurocentres Vocabulary Test (Meara and Jones, 1990). Laufer (1992b) indicated that the lexical threshold for reading comprehension is $95 \%$ which corresponds to knowing about 3000-word family level of Nation's (1983) test. That is, L2 learners reading comprehension in English will be impeded by having a vocabulary size below 3,000 word families. Another research study by Coady et.al. (1993) further confirmed that explicit learning of 3,000 high frequency English words produces considerable positive effect on reading comprehension of English language learners. And finally, in two more recent studies (e.g., Qian ,1999, 2002) on the relation of vocabulary knowledge and reading comprehension, 3,000 word level, as measured by Nation's (1990) vocabulary Levels Test, was considered as the minimum lexical threshold level for reading comprehension of learners of English.

\section{Empirical Studies on L2 Lexical Knowledge and Reading Comprehension}

A number of empirical studies investigated the roles of second language vocabulary knowledge in reading comprehension. Koda's (1989) study of 24 college students who were learning Japanese as a foreign language found equally strong correlations between a self-made vocabulary test and two reading tests, one being a cloze test and the other paragraph comprehension. Koda (1989) reported a correlation of $.69(\mathrm{r}=.69)$ between the learners' scores on the vocabulary test and the cloze test and a correlation of $.74(\mathrm{r}=.74)$ between their scores on the vocabulary test and the paragraph comprehension test. Another research study by Coady et. al. (1993), which studied 79 students learning English in a university academic program revealed that the two experimental groups, receiving special training in high frequency vocabularies, achieved better reading comprehension at the end of experiment than did the control group, not receiving such a treatment. Besides, in his study, Khalidieh (2000) concluded that Arabic learners' lack of morphological knowledge, a subcomponent of vocabulary knowledge, prevented the learners from arriving at an interpretation of authentic Arabic texts. The predictive power of L2 vocabulary in reading comprehension was also explored by Stal (2003) who called the relationship between vocabulary and reading comprehension a "robust" one and asserted that vocabulary knowledge has consistently been the "foremost predictor of a text's difficulty" (p.241). In his study of $5^{\text {th }}$ grade students, Stal (2003) reported that vocabulary knowledge and reading comprehension were strongly correlated, based on a measurement of word difficulty and sentence difficulty. In addition, Anderson and Freebody (1981) maintained, “a reader's general vocabulary knowledge is the single best predictor of how well that reader can understand a text" (p.3), based on their study of $8^{\text {th }}$ grade students, who were assessed using word recognition checklists and multiple choice vocabulary tasks. The authors reported a high correlation between tests of vocabulary and reading comprehension.

\section{E. The Roles of L2 Vocabulary Breadth and Depth in Reading Comprehension}

In second language research few empirical studies have been reported on the relationship between depth and breadth of vocabulary knowledge and reading comprehension. In one study, Laufer (1992b) administered the Vocabulary Levels Test (Nation, 1983) and Eurocentres Vocabulary Test (Meara and Jones, 1990) to 92 university freshmen whose native language was either Arabic or Hebrew. She found that the scores on these tests correlated with reading comprehension scores at $.50(\mathrm{r}=.50)$ and $.75(\mathrm{r}=.75)$ respectively. Qian (1999) found more robust correlations in his study of 44 Korean learners and 33 Chinese learners of English, using Vocabulary Levels Test (Nation, 1983) and reading comprehension section of the TOEFL. The correlation between the two tests was .78. Beglar and Hunt (1999) conducted an almost identical study with 496 Japanese high school students using two versions of 2,000 word level and 
464 students with two versions of University Word List (UWL) of Vocabulary Levels Test (Nation,1983). They found that the scores on the reading comprehension section of the TOEFL test correlated with the scores on two versions of the 2,000 word level at .66 $(\mathrm{r}=.66)$ and $.62(\mathrm{r}=.62)$, respectively, and with the scores on the two versions he UWL section at $.67(\mathrm{r}=.67)$ and $.71(\mathrm{r}=.71)$ respectively. Still, in another study which investigated the relationship between the perceived reading comprehension strategies, vocabulary size and reading comprehension of 226 first year EFL learners of 7 different higher education institutions in Saudi Arabia, Al Nujaidi (2003) found a strong positive relationship between the participants' vocabulary size at 2000 level and their performance on a reading comprehension test.

In comparison to vocabulary size, there have been fewer studies exploring the relationship between depth of vocabulary knowledge and reading comprehension. In one study, de Bot et.al (1997) aimed to model L2 lexical processing in the context of reading comprehension through interview and think aloud protocols. Although de Bot et.al. (1997) did not intend to probe the connection between depth of vocabulary knowledge and reading comprehension, their study found that various aspects of vocabulary knowledge, such as word morphology, word associations and other vocabulary depth indicators are closely linked to reading comprehension process. In another study, Qian (1999) found a strong correlation of $.82(\mathrm{r}=.82)$ between the vocabulary depth of 44 Korean and 33 Chinese learners of English, using Word Associates Test (Read, 1995), and their reading comprehension.

\section{METHOD}

\section{A. Participants}

A group of 112 senior and junior students majoring in English Literature at Shiraz University, Iran, took part in this study. The participants were male and female students between 21 to 25 years old.

Although 112 students took part in this study, 81 homogenized students were chosen as the participants of this study. To find the homogenized group, the participants were selected among those who had reached the lexical threshold level, i.e. the 3,000 word family level or better. Of the total 112 participants of this study, eight participants did not reach the 3,000 word family level. Besides, since the three tests, test of reading comprehension, vocabulary size and vocabulary depth, were administered in single testing sessions, there were 23 participants who did not take part in all three tests and thus were excluded from the participants of the study.

\section{B. Instrumentation}

The following instruments used in this study:

A reading comprehension test taken from Longman TOEFL (Philips, 2006).

A vocabulary size test called Vocabulary Levels Test (Schmitt, 2001).

A depth of vocabulary knowledge test called Word Associates Test (Read, 1995)

The characteristics of each of the three tests will be presented below:

Reading Comprehension Test

The reading comprehension test $(\mathrm{RC})$ items used in this research study were taken from Longman TOEFL (Philips, 2006). The reading comprehension test included three passages. There were 30 multiple choice questions in total (See Appendix 1).

Vocabulary Size Test

The English vocabulary size test (VS) chosen for this study was Vocabulary Levels Test (Schmitt, 2001) (See Appendix 2).

It is in five sections, representing five different word frequency levels-the 2,000-word level, the 3,000-word level, the 5,000-word level, the Academic Vocabulary level and the 10,000-word level. The 2,000- and 3,000-word level sections include only high-frequency words in English; the 5,000-word level is a boundary level between the high-frequency and low-frequency word levels; the 10,000-word level section includes relatively low-frequency words; and the Academic vocabulary section contains medium-frequency academic vocabulary.

At each level, the test takers need to check 60 words against 30 definitions to make the correct matches. In addition, the words used in the definitions are always more common than the matched words (Schmitt et al., 2001). The validity and reliability of the Vocabulary Levels Test has been confirmed by a number of researchers (e.g., Schmitt et. al. 2001 Beglar and Hunt, 1999; Read, 1998) and it has also been used by a number of researchers (e.g., Qian, 2002, 1999; Luafer and Paribakht, 1998; Yu, 1996) as an appropriate means of assessing vocabulary size of English language learners. Schmitt etal. (2001) in his study which tested a total of 801 participants in 13 groups in England, New Zealand, Slovakia, Brazil and Spain, in which he compared the scores from two versions of the test, namely, Schmitt (2001, 2000) found that reliability coefficients ranged from .92 to .96 for different sections of the tests. In his study to examine the validity of the VLT (Schmitt, 2000, 2001), Schmitt etal. (2001) realized that nine native speakers had no problems with the two versions of the test and all of them reached the maximum or near maximum scores. Besides, the results from the 801 participants were analyzed using the ITEMAN (1989).Schmitt et al. (2001) concluded the mean facility value decreases as the levels contain words that are progressively less frequent. The mean discrimination indices varied from .509 to .669. For levels other than the 10,000 level, no item had a discrimination index of less than .30 at the 10,000 level, the discrimination fell below .30 in 13 out of 60 cases. They concluded that the discrimination indices for 
the VLT are acceptable, bearing in mind that it is quite usual for less able learners to know a certain number of lowfrequency words, while more able learners typically have some gaps in high frequency vocabulary.

The results of the analysis of the profile of the sections, using Guttman Scalability analysis, revealed that the four frequency sections had a high degree of scalability. In most cases, therefore, if an examinee reached the criteria at one level, the teacher or the researcher can be reasonably confident that the higher frequency levels are known as well. The results of the factor analysis for separate sections and all of the sections together revealed that the only apparent linguistic feature that the VLT could address is vocabulary (Schmitt etal. 2001).

Depth of Vocabulary Knowledge Test

The depth of vocabulary knowledge test (DVK) in this study was Word Associates Test, version 4.0 (Read, 1995) (See Appendix 3).

The WAT intends to assess depth of vocabulary knowledge through word associations; the semantic and collocational relationships that a word has with other words in a language.

Each test item comprises one stimulus word, which is always an adjective and eight words located in two different columns, each containing four words. Among these eight words, four are associates (i.e., related words) to the stimulus word and the other four are distractors.

WAT went through a process of repeated piloting and drafting, including a large-scale field test involving 132 participants. In one trial $(\mathrm{N}=94)$ a high correlation of .82 was found between the WAT and a comparison vocabulary matching test. The IRT reliability of the WAT in this trial was .93 and that of the matching test was .90 (Read, 1995). In an earlier trial $(\mathrm{N}=38)$ a correlation of .85 was reported between the WAT and the matching test (Read, 1994). Read (1998) continued revising and improving the test and found high correlations between the WAT and one matching test of vocabulary knowledge, and an interview. In addition to be a reliable test, the WAT has been used to measure the depth of lexical knowledge in a number of lexical studies (e.g., Nassaji, 2006, 2004; Qian, 2002, 1999).

\section{Procedures}

\section{Data Collection}

Before being administered to the participants of the main study, the three tests- reading comprehension, vocabulary size and vocabulary depth- were piloted with 20 seniors at Shiraz University. The primary purposes of this pilot study were to decide how to provide enough instructions to the participants and to determine the time that test-takers would need to complete the tests.

Based on the findings of the pilot study, the same instructions were provided by the researcher, and the same amount of time was devoted to the completion of the three language tests. The three tests, the reading comprehension (RC), vocabulary size (VS), and depth of vocabulary knowledge (DVK), were administered in single testing sessions to the participants. To eliminate the possibility of an order effect, the tests were administered in counterbalanced orders to the four groups of the participants. The orders are listed as follows:

1). VS- DVK- RC

2). VS- RC-DVK

3). DVK- RC- VS

4). RC-DVK- VS

2. Data Analysis

To explore the level of intercorrelations among vocabulary size, vocabulary depth, and reading comprehension twotailed Pearson correlation, using SPSS version 11.5 for windows, was conducted. When determining the more powerful predictor of reading comprehension, multiple regression analysis was conducted.

\section{RESULTS AND DisCUSSION}

A two-tailed Pearson correlation analysis was conducted to see if there is any significant relationship between depth of vocabulary knowledge and reading comprehension of Iranian EFL University students. Table 1 illustrates clearly the correlational analysis of vocabulary depth scores, and reading comprehension test scores.

TABLE 1.

TWo-TAILED PEARSON CORRELATION BETWEEN DEPTH OF VOCABULARY KNOWLEDGE (DVK) AND READING COMPREHENSION (RC)

\begin{tabular}{|l|l|l|l|}
\hline & & RC & DVK \\
\hline RC & Pearson & 1 & $.734(* *)$ \\
& Correlation & & .000 \\
& Sig. (2-tailed) &. & 81 \\
N & 81 & 1 \\
& Pearson & $.734(* *)$ & \\
& Correlation & .000 &. \\
& Sig. (2-tailed) & 81 & 81 \\
\hline
\end{tabular}

** Correlation is significant at the 0.01 level (2-tailed). 
In light of the results of the Pearson correlation, as can be seen in the Table1, the correlation between depth of vocabulary knowledge and reading comprehension test scores is $.73(\mathrm{r}=.73)$. Since the significance value for the correlation between vocabulary depth and reading comprehension is much less than $0.01(\mathrm{p}<0.01)$, one can conclude that depth of vocabulary knowledge and reading comprehension are positively correlated.

To investigate the fact that to what extent scores on the breadth of vocabulary correlated with those of reading comprehension, a two-tailed Pearson correlation analysis was conducted between the scores obtained through the administration of vocabulary size test and reading comprehension test. Table 2 depicts the correlational analysis of vocabulary size (VS) scores and reading comprehension (RC) test scores.

TABLE 2

Two-TAILED PEARSON CORRELATION BETWEEN VOCABUlary SiZE (VS) AND READING COMPREHENSION (RC)

\begin{tabular}{|l|l|l|l|}
\hline & & RC & VS \\
\hline RC & Pearson & 1 & $.834(* *)$ \\
& Correlation & & .000 \\
& Sig. (2-tailed) &. & 81 \\
& N & 81 & 1 \\
PS & Pearson & $.834(* *)$ &. \\
& Correlation & .000 & 81 \\
& Sig. (2-tailed) & 81 & N \\
& N* Correlation is significant at the 0.01 level (2-tailed).
\end{tabular}

The results of the Pearson correlation, as can be seen in Table 2, shows that the correlation between vocabulary size and reading comprehension test scores is $.83(\mathrm{r}=.83)$. The significance column of the same table shows the significant value for the correlation between these two sets of variables is much less than $0.01(\mathrm{P}<0.01)$, so it is not hard to conclude that vocabulary size and reading comprehension are highly related.

At the third step, multiple regression analyses were conducted to predict the reading comprehension performance from, on one hand, vocabulary size, and on the other hand, depth of vocabulary knowledge. To determine the more powerful predictor of reading comprehension, scores on the vocabulary size (VS) and depth of vocabulary knowledge (DVK) were taken as the predictor (or independent) variables and scores on the reading comprehension (RC) as the criterion (or dependent) variable. Through a multiple regression analysis using SPSS, hierarchical multiple regression analyses was chosen. With this method, variables or sets of variables are entered in steps, with each independent variable being assessed in terms of what it adds to the prediction of the dependent variable, after the previous variables are controlled (Pallant, 2001).

TABLE 3

THE RESUltS OF HIERARCHICAL MULTIPLE REGRESSION

\begin{tabular}{|c|c|c|c|c|c|}
\hline & Adjusted $\mathbf{R}^{2}$ & $\mathbf{R}^{2}$ & B & $\beta$ & Sig \\
\hline $\begin{array}{ll}\text { DVK } & \text { RC } \\
\text { VS } & \\
\text { VS,DVK } & \\
\end{array}$ & $\begin{array}{l}.532 \\
.692 \\
.772 \\
\end{array}$ & $\begin{array}{l}* * .538 \\
* * .696 \\
* * .778 \\
\end{array}$ & $\begin{array}{l}.114 \\
.197\end{array}$ & $\begin{array}{l}* * .360 \\
* * .615\end{array}$ & $\begin{array}{l}.000 \\
.000 \\
.000\end{array}$ \\
\hline
\end{tabular}

As Table 3 shows both vocabulary size (VS) and depth of vocabulary knowledge (DVK) contribute significantly to the reading comprehension performance of the participants of the present study. As it can be seen, vocabulary size accounted for $69.6 \%\left(\mathrm{R}^{2}=.696\right)$ and vocabulary depth accounted for $53.8 \%\left(\mathrm{R}^{2}=.538\right)$ of the variance in reading comprehension of the participants of this study. Besides, the standardized regression coefficients $(\beta)$ indicate that both vocabulary size and depth contributed significantly to the reading comprehension performance of the test takers. The above Table further shows that vocabulary size contributes more to the reading comprehension performance of the test takers than vocabulary depth, the standardized regression coefficient index $(\beta)$ is .615 for vocabulary size and .360 for vocabulary depth.

\section{CONCLUSIONS}

Summarizing the answers for the research questions, it was found that, with the sample of Iranian EFL learners participated in this research study, scores on the depth of vocabulary knowledge, breadth of vocabulary knowledge and reading comprehension are closely related. Besides, the significance value showed that although vocabulary size correlated more strongly to reading comprehension than depth of vocabulary knowledge, the magnitudes of the correlation coefficients between each predictor variable and the criterion value do not differ significantly. Moreover, the correlations between depth and breadth of vocabulary knowledge and reading comprehension in this study are fairly close to their corresponding counterparts in Qian's (1999) Laufer's (1992b) Beglar and Hunt's (1999) Al Nujaidi's (2003) studies.

The results of the multiple-regression analysis indicate that, first, the dimension of depth of vocabulary knowledge is as important as that of vocabulary size: the two dimensions are closely associated with reading comprehension. Since the reading comprehension test in the present study aimed to measure the reading comprehension performance of 
Iranian EFL University students, one can thus proceed to state that, for the EFL University Students and in academic settings, depth and breadth of vocabulary are closely and positively associated with the reading comprehension performance. In determining the more powerful predictor of reading comprehension from vocabulary size and vocabulary depth, the results obtained in this study runs against the findings of the Qian's (1999) study. Qian (1999) found that for the 77 Korean and Chinese English language learners participated in his study vocabulary depth contributed more to the reading comprehension of the test takers than vocabulary breadth. Although the results of the present research question run against that of Qian's (1999) study, these results do not seem surprising at the moment due to the stronger correlation with reading comprehension that vocabulary size shows in this study. Among vocabulary size and depth the one that has a stronger relationship with reading comprehension would be the more powerful predictor of reading comprehension. In this study the results suggest vocabulary size to be a stronger predictor of reading comprehension than vocabulary depth. In addition, since the empirical results have shown that vocabulary size and depth measures are similarly powerful in predicting reading comprehension, it would make sense to give equal weight to these two components of vocabulary knowledge in reading comprehension assessment.

\section{LIMITATIONS AND FUTURE RESEARCH}

Acknowledging some limitations through the accomplishment of different phases, several suggestions made for further research. First, a relationship between vocabulary knowledge and reading comprehension was found to exist in this study; however, whether this relationship involved casualty was not investigated. Further research to investigate this causal relation can study the comparison between two different vocabulary enhancement treatments, such as reading only and reading plus. Next, the present research study employed only one type of vocabulary size measure (Schmitt, 2001) and vocabulary depth measure (Read, 1995) to assess the test takers' depth and size of vocabulary knowledge. The same research can be replicated using other vocabulary size tests, e.g. Eurocentres Vocabulary Size Test (Meara and Buxton, 1987; Meara and Jones, 1988, 1990), Productive Vocabulary Levels Test (Laufer and Nation, 1995) and vocabulary depth measures, e.g. Wesche and Paribakht's $(1993,1996)$ Vocabulary Scale Knowledge. Finally, the present research investigated the contribution of vocabulary knowledge to reading comprehension. The research did not look into the relationship between vocabulary knowledge and other language skills. Meara and Jones (1988) suggested that vocabulary knowledge is heavily implicated in all language skills, so future studies can be conducted to determine whether vocabulary knowledge can contribute significantly to the performance of English language learners in other language skills, i.e. listening comprehension, speaking and writing.

\section{APPLICATIONS AND IMPLICATIONS OF THE FINDINGS}

The findings of this study could prove to be a particularly useful guideline for curriculum designers and material developers. The present research study shows that Iranian EFL University students' depth and size of vocabulary knowledge are strongly associated with their reading comprehension success. Now it is up to the curriculum designers and material developers to incorporate these aspects of vocabulary knowledge in EFL syllabi and materials.

It is also hoped that the findings of the present research can be useful in teaching English as a foreign language. As the results of the present study reveals for Iranian EFL learners both their depth and breadth of L2 lexical knowledge are fundamental components in the vocabulary knowledge-reading comprehension chain. The major trust of this finding is to make the teachers create an awareness of the importance of vocabulary knowledge, both depth and breadth, in the language learners. As Schmitt (1990) suggested what language learners become conscious of, what they pay attention to, and what they notice, influence and in some ways determine the outcome of their learning. Since language is vast and teachers cannot teach all words learners need, it will be highly desirable to raise the language learners' awareness of the importance of paying attention to developing their depth and breadth of vocabulary knowledge while learning English as a foreign language.

\section{ApPendix 1: ReAding Comprehension Test (SAMPle Questions of ReAding Comprehension TeSt Developed by PHILIPS, 2006)}

Carbon tetrachloride is a colorless and inflammable liquid that can be produced by combining carbon disulfide and chlorine. This compound is widely used in industry today because of its effectiveness as a solvent as well as its use in the production of propellants.

Despite the widespread use in industry, carbon tetrachloride has been banned for home use. In the past, carbon tetrachloride was a common ingredient in cleaning compounds that were used throughout the home, but it was found to be dangerous: when heated, it changes into a poisonous gas that can cause severe illness and even death if it is inhaled. Because of this dangerous characteristic, the United States revoked permission for the home use of carbon tetrachloride in 1970.The United States has taken similar action with various other chemical compounds.

1. The main point of this passage is that

(A) carbon tetrachloride can be very dangerous when it is heated

(B) the government banned carbon tetrachloride in 1970

(C) although carbon tetrachloride can legally be used in industry, it is not allowed in home products 
(D) carbon tetrachloride used to be a regular part of cleaning compounds.

2. The word "widely" in line 2 could most easily be replaced by

(A) grandly

(B) extensively

(C) largely

(D) hugely

3.The word "banned" in line 4 is closest in meaning to

(A)forbidden

(B) allowed

(C) suggested

(D) instituted

4. According to the passage, before 1970 carbon tetrachloride was

(A) used by itself as a cleanser

(B) banned in industrial use

(C)often used as a component of cleaning products

(D) not allowed in home cleaning products

5.It is stated in the passage that when carbon tetrachloride is heated, it becomes

(A) harmful

(B) colorless

(C) a cleaning compound

(D) inflammable

6. The word "inhaled" in line 7 is closest in meaning to

(A) warmed

(B) breathed in

(C) carelessly used

(D) blown

7. The word "revoked" in line 8 could most easily be replaced by

(A) gave

(B) granted

(C) instituted

(D) took away

8. It can be inferred from the passage that one role of the U.S. government is to

(A) regulate product safety

(B) prohibit any use of carbon tetrachloride

(C) instruct industry on cleaning methodologies

(D) ban the use of any chemicals

9. The paragraph following the passage most likely discusses

(A) additional uses for carbon tetrachloride

(B) the banning of various chemical compounds by the U.S. government

(C) further dangerous effects of tetrachloride

(D) the major characteristics of carbon tetrachloride

ApPendix 2: Vocabulary Size Test (Sample Questions of Vocabulary LeVels Test DeVeloped by Schmitt, 2001)

The 2,000 word level

1 copy

2 event

3 motor

4 pity

5 profit

6 tip

1 coffee

2 disease

3 justice

4 skirt

5 stage

6 wage end or highest point
this moves a car things made to be like another

1clerk

money for work

a piece of clothing

using the law in the right way 


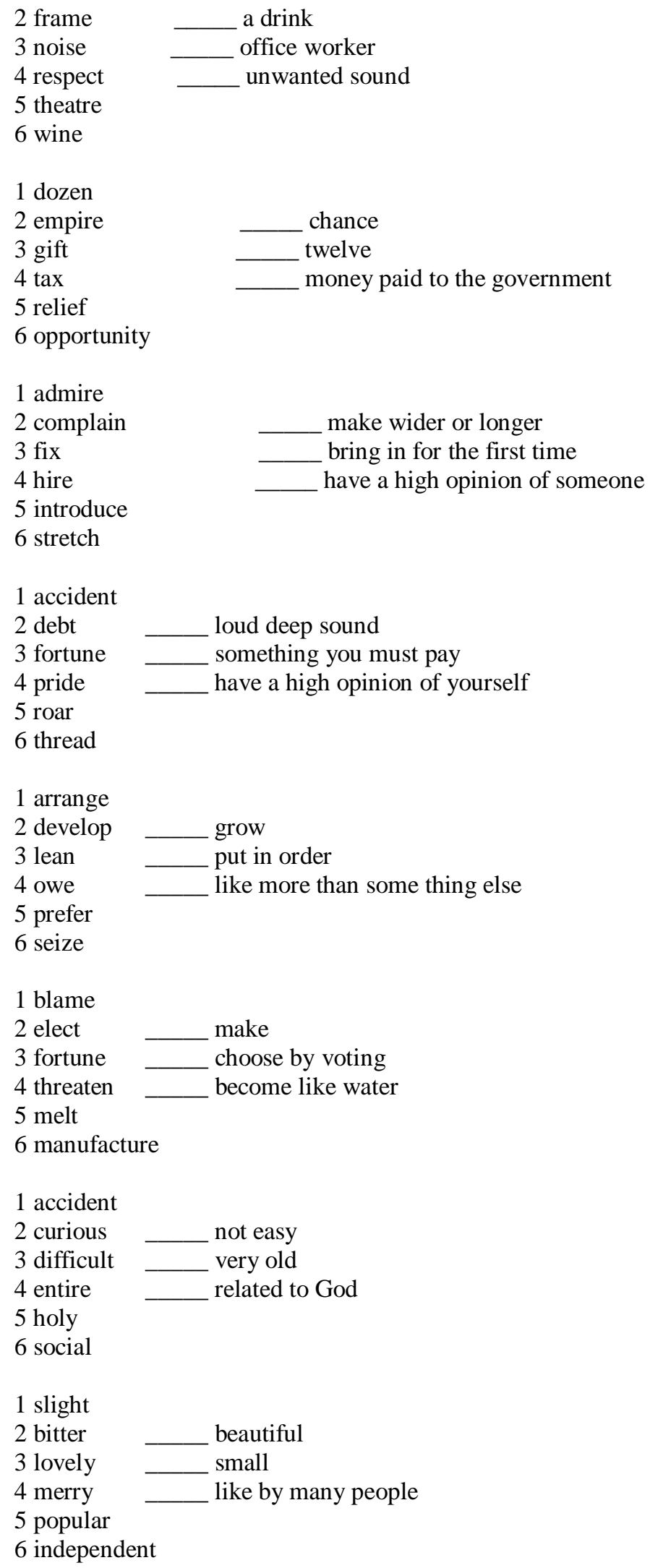

ApPENDiX 3: DePth of Vocabulary KnOWledge Test: (SAMPle Questions of Word Associates Test DEVELOPED BY READ, 1995) 


\section{1 beautiful}

\begin{tabular}{|l||l|}
\hline enjoyable expensive free loud & education face music weather \\
\hline
\end{tabular}

2 bright

\begin{tabular}{|l||ll|}
\hline clever famous happy shining & colour hand poem taste \\
\hline
\end{tabular}

3 calm'

\begin{tabular}{|ll||l|l|}
\hline open quiet smooth tired & cloth day light person \\
\hline
\end{tabular}

4 natural

\begin{tabular}{|l||l|l|}
\hline expected helpful real short & foods neighbours parents songs \\
\hline
\end{tabular}

5 fresh

\begin{tabular}{|l||ll|}
\hline another cool easy raw & cotton heat language water \\
\hline
\end{tabular}

6 general

\begin{tabular}{|l||l|l}
\hline closed different usual whole & country idea reader street
\end{tabular}

7 bare

\begin{tabular}{|l||lll}
\hline empty & heavy uncovered useful & cupboard feet school tool
\end{tabular}

8 acute

\begin{tabular}{|ll||ll|}
\hline hidden often rich sharp & angle hearing illness stones \\
\hline
\end{tabular}

\section{9 common}

\begin{tabular}{|l||l|}
\hline complete light ordinary shared & boundary circle name party \\
\hline
\end{tabular}

\section{0 complex}

\begin{tabular}{|ll||ll}
\hline angry difficult & necessary sudden & argument passengers patterns problem \\
\hline
\end{tabular}

\section{1 broad}

\begin{tabular}{|l||ll|}
\hline full moving quiet wide & night river shoulders smile \\
\hline
\end{tabular}

\section{2 conscious}

\begin{tabular}{|l||l|l|}
\hline awake healthy knowing laughing & face decision effort student \\
\hline
\end{tabular}

\section{3 convenient}

\begin{tabular}{|ll||ll|}
\hline easy & fresh near suitable & experience sound time vegetable \\
\hline
\end{tabular}

\section{4 dense}

\begin{tabular}{|l||ll||}
\hline crowded hot noisy thick & forest handle smoke weather \\
\hline
\end{tabular}

\section{ACKNOWLEDGEMENT}

The authors are grateful to the faculty members of Shiraz University, Iran and Isfahan University, Iran for their help and support.

\section{REFERENCES}

[1] Al Nujaidi, A. H. (2003). The relationship between vocabulary size and reading comprehension of EFL learners in Saudi Arabia. Unpublished PhD Dissertaion, Oklahoma State University.

[2] Anderson,R.C. and Freebody, P.(1981). Vocabulary knowledge. In J.T. Cutterie (Ed.), Comprehension and Teaching: Research Review, pp. 77-117 New York; International Reading Association.

[3] Beglar, D. and Hunt, A. (1999). Revising and validating the 2000 word-level and university word-level vocabulary tests. Language Testing, 16, 131-162.

[4] Chapppelle, C. A. (1994). Are c-tests valid measures for L2 vocabulary research? Second Language Research, 10, 157-187.

[5] Chapppelle, C. A. (1998). Construct definition and validating inquiry in second language acquisition research. In L. F. Bachman and A. D. Cohen (Eds.), Interfaces between Second Language Acquisition and Language Testing Research, pp. 32-70. Cambridge: Cambridge University Press.

[6] Clark, M. A. (1979). Reading in Spanish and English: Evidence from adult ESL students. Language learning, 29, $121-150$.

[7] Clark, M. A. (1980). The short-circuit hypothesis of ESL reading or when language competence interferes with reading performance. Modern Language Journal, 64, 203-209.

[8] Coady, J., Magoto,J., Hubbard, P., Graney, J. and Mokhtari, K. (1993). High frequency vocabulary and reading proficiency in ESL readers. In T. Huckin, M. Haynes and J. Coady (Eds.), Second language reading and vocabulary learning. Norwood, NJ: Ablex.

[9] Cronbach, L. J. (1942). An analysis of techniques for diagnostic vocabulary testing. Journal of Educational research, 36, 206- 
217.

[10] Cummins, J (1979). Cognitive academic language proficiency, linguistic interdependence, the optimum age acquisition and other matters Working Papers in Bilingualism, 19.107-205.

[11] De Bot, K., Paribakht, T. S. and Wesche, M. B. (1997). Toward a lexical processing model for the study of second language vocabulary acquisition: Evidence from ESL reading. Studies in Second language Acquisition, 19, 309-329.

[12] Grabe, W. (1991). Current developments in second language research. TESOL Quarterly, 25, 375-406.

[13] Haastrup, K. and Henriksen, B. (2000). Vocabulary acquisition: Acquiring depth of knowledge through network building. International Journal of Applied Linguistics, 10, 221-240.

[14] Henriksen, B. (1999). Three dimensions of vocabulary development. Studies in Second Language Acquisition, 21, 303-317.

[15] Hisch, D. and Nation, I. S. P. (1992). What vocabulary size is needed to read simplified texts for pleasure? Reading in a Foreign Language, 8, 689-696.

[16] ITEMAN (1989). St. Paul, MN: Newbury House

[17] Khaldieh, S. A. (2000). Second language reading proficiency: Reader-text interaction, strategy use and comprehension processes. Paper presented at the 22nd Annual Conference on the Teaching of Foreign Language and Literature, Youngstone, $\mathrm{OH}$.

[18] Koda, K. (1989). The effects of transferred vocabulary knowledge on the development of L2 reading proficiency. Foreign Language Annals, 22, 529-540.

[19] Laufer, B. (1989). What percentage of text-lexis is essential for reading comprehension. In C. Lauren and L. Norman (Ed.), Special Language; From humans thinking to thinking machines. Clevedon: Multilingual Matters.

[20] Laufer, B. (1992 b). How much lexis is necessary for reading comprehension? In H. Bejoint and P. Arnuad (Eds.), Vocabulary and Applied Linguistics, pp. 126-132. London: Macmillan.

[21] Laufer, B. (1996). The lexical threshold of second language reading comprehension: what it is and how it relates to L1 reading ability. In K. Sajavaara and C. Fairweather (Eds.), Approaches to Second Language Acquisition, pp. 55-62. Jyvaskyla: University of Jyvaskyla.

[22] Laufer, B. (1997). The lexical plight in second language reading: words you don't know, words you think you know and words you can't guess. In J. Coady \& T. Huckin (Eds.), Second Language Vocabulary Acquisition, pp. 20-34. Cambridge: Cambridge University Press.

[23] Laufer, B., and Hulstijn, J. (2001). Incidental vocabulary acquisition in a second language: The construct of task-induced involvement. Applied Linguistics, 22(1), 1-26.

[24] Laufer, B., and Nation, I.S.P. (1995). Vocabulary size and use: Lexical richness in L2 written production. Applied Linguistics, 16(3), 307-322.

[25] Laufer, B., and Paribakht, S. (1998). The relationship between passive and active vocabularies: effects of language learning context. Language Learning, 48(3), 365-391.

[26] Laufer, B., and Sim, D. D. (1985a). Measuring and explaining the reading threshold needed for English for academic purposes texts. Foreign Language Annals, 18(5), 405-411.

[27] Meara, P. (1996). The dimensions of lexical competence. In G. Brown, K. Mamkyaer and J. Williams (Eds.), Performance and competence in second language acquisition. Cambridge: Cambridge University Press.

[28] Meara, P., and Buxton, B. (1987). An alternative to multiple choice vocabulary tests. Language Testing, 4(2), $142-151$.

[29] Meara, P., \& Jones, G. (1988). Vocabulary size as a placement indicator. In P. Grunwell (Ed.), Applied Linguistics in Society, pp. 80-87. London: Center for Information on Language teaching and research

[30] Meara, P., \& Jones, G. (1990). Eurocentres Vocabulary Size Test 10KA. Zurich: Eurocentres Learning Service.

[31] Nagy, W. E., \& Scott, J. A. (2000). Word schemas: expectations about the form and meaning of new words. Cognition and Instruction, 7(2), 105-127.

[32] Nassaji, H. (2004). The relationship between depth of vocabulary knowledge and L2 lexical inferencing, strategy use and success. Canadian Modern Language Review, 1, 107-134.

[33] Nassaji, H. (2006). The relationship between depth of vocabulary knowledge and L2 lexical inferencing, strategy use and success. Modern Language Journal, 90 (3), 387-401.

[34] Nation, I. S. P. (1983). Testing and teaching vocabulary. Guidelines, 5(1), 12-25.

[35] Nation, I. S. P. (1990). Teaching and Learning Vocabulary. Rowley, Mass: Newbury House.

[36] Nation, I. S. P. (1993). Vocabulary size, growth and use. In R. Schreuder and B. Weltens (Eds.), The Bilingual Lexicon, 115134. Amsterdam/Philadelphia: John Benjamins.

[37] Nation, I. S. P. (1996). Vocabulary learning and intensive reading. EA Journal, 21(2), 20-29.

[38] Nation, I. S. P. (2001). Learning vocabulary in another language. Cambridge: Cambridge University Press.

[39] Nation, I. S. P., and Waring, R. (1997). Vocabulary size, text coverage, and word lists. In N. Schmitt and M. McCarthy (Eds.), Vocabulary: Description, acquisition and aedagogy, pp. 6-19. Cambridge: Cambridge University Press.

[40] Ordonez, C. A., Carrol, M.S., Snow, C. E., McLaughlin, B. (2002). Depth and breadth of vocabulary knowledge in two languages: Which transfer? Journal of Educational Psychology, 94 (4), 719-728.

[41] Pallant, J. (2001). SPSS survival manual: A step by step guide to data analysis using SPSS for windows (Version 10 and 11 ). Buckingham/ Philadelphia: Open University Press.

[42] Philips, D. (2006). Longman complete course for TOEFL test. New York: Longman Group.

[43] Qian, D. (1998). Depth of vocabulary Knowledge: Assessing its role in adults' reading comprehension in English as a second language. Unpublished $\mathrm{PhD}$ Dissertation, University of Toronto.

[44] Qian, D. (1999). Assessing the roles of depth and breadth of vocabulary knowledge in reading comprehension. Canadian Modern Language Review, 56(2), 282-307.

[45] Qian, D. (2002). Investigating the relationship between vocabulary knowledge and academic reading performance: an assessment perspective. Language Learning, 52(3), 513-536.

[46] Read, J. (1988). Measuring the vocabulary knowledge of second language learners. RELC Journal, 19(2), 12-25. 
[47] Read, J. (1989). Towards a deeper assessment of vocabulary knowledge. Paper presented at the $8^{\text {th }}$ congress of the International Association of Applied Linguistics. Sydney, Australia.

[48] Read, J. (1994). Refining the Word Associates Format as a measure of depth of vocabulary knowledge. Paper presented at the $19^{\text {th }}$ Annual Congress of the Applied Linguistics Association of Australia. Melbourn, Australia.

[49] Read, J. (1995). Refining the word associates format as a measure of depth of vocabulary knowledge. New Zealand Studies in Applied Linguistics, 1, 1-17.

[50] Read, J. (1998). Validating a test to measure depth of vocabulary knowledge. In A. J. Kunnan (Ed.), Validation in Language Assessment, pp. 41-60. Mahwah, N.J.: Lawrence Erlbaum Associates.

[51] Read, J. (2004). Assessing Vocabulary. Cambridge: Cambridge University Press.

[52] Richards, J. C. (1976). The role of vocabulary teaching. TESOL Quarterly, 10(1), 77-89.

[53] Schwanenflugel, P. J., Stahl, S. A., and McFalls, E. L. (1997). Partial word knowledge and vocabulary growth during reading comprehension. Journal of Literacy Research, 29(4), 531-553.

[54] Schmitt, R. (1990). Imput, interaction, attention, and awareness: The case for consciousness raising in the second language teaching. Paper presented at Enpuli Encontro National Professors Universities de Lengua Inglea, Rio de Janeiro.

[55] Schmitt, N. (2000). A framework for second language vocabulary assessment. Language Testing, 18, 1-32.

[56] Schmitt, N. (2001). Tracking the incremental acquisition of second language vocabulary acquisition: a longituadinal study. Language learning 48, 281-317.

[57] Schmitt, N., Schmitt, D., and Clapham, C. (2001). Developing and exploring the behaviour of two new versions of the Vocabulary Levels Test. Language Testing, 18(1), 55-88.

[58] Stal, S. (2003). Vocabulary and readability: How knowing word meanings affects comprehension. Topics in Language Disorders, 23 (3), 241-247.

[59] Sutarsyah, C., Nation,I. S. P., and Kennedy, G. (1994). How useful is EAP vocabulary for ESP? A corpus based study. RELC Journal, 25(2), 34-50.

[60] Wesche, M. B. and Paribakht, T. S., (1993). Reading comprehension and second language development in a comprehensionbased ESL program. TESL Canada Journal, 11(1), 9-27.

[61] Wesche, M. B. and Paribakht, T. S., (1996). Enhancing vocabulary acquisition through reading: a hierarchy of text-related exercise types. The Canadian Modern Language Review, 52(2), 155-178.

[62] Yu, L. (1996). The role of cross-linguistic lexical similarity in the use of the motion verbs in English by Chinese and Japanese learners. Unpublished PhD Dissertation, University of Toronto.

Ahmad Moinzadeh is an Assistant Professor and teaches graduate courses in Applied Linguistics at University of Isfahan.

Roghaieh Moslehpour is an EFL instructor and teaches English at different language schools. She has received her B.A. in English Literature from Shiraz University and her M.A. in TEFL, from University of Isfahan. 